\title{
A DFT study on the adsorption of benzodiazepines to vermiculite surfaces
}

\author{
A. J. Palace Carvalho • A. V. Dordio • \\ J. P. Prates Ramalho
}

Received: 28 February 2014 / Accepted: 8 June 2014 /Published online: 11 July 2014

(C) Springer-Verlag Berlin Heidelberg 2014

\begin{abstract}
Widespread use of pharmaceuticals such as benzodiazepines has been resulting over the last decades in the dissemination of residues of these compounds in the environment, and such fact has been raising increasing concern. The generally low efficiencies of conventional wastewater treatment processes for the removal of this type of pollutants demands for the development of alternative or complementary water and wastewater treatment technologies, among which adsorption processes have been gaining popularity, provided that cheap efficient adsorbents are found. Clay materials have been one of the popular choices in this regard. In the present study, quantum chemical calculations have been performed by periodic DFT using the projector augmented-wave (PAW) method to characterize the interactions of two benzodiazepine molecules, alprazolam and diazepam, with a surface of clay mineral, vermiculite. It was observed that both molecules interact strongly with the vermiculite surface, both through a water-bridge binding and by cation-bridge provided by the exchangeable $\mathrm{Mg}^{2+}$ cations of the vermiculite surface. The results point to an interesting potential of vermiculite to be
\end{abstract}

This paper belongs to Topical Collection QUITEL 2013

A. J. P. Carvalho $(\bowtie) \cdot$ A. V. Dordio · J. P. P. Ramalho

Department of Chemistry, Sciences and Technology School,

University of Évora, Rua Romão Ramalho 59,

7000-671 Évora, Portugal

e-mail: ajpalace@uevora.pt

A. J. P. Carvalho · J. P. P. Ramalho

CQE - Centro de Química de Évora, University of Évora, Rua

Romão Ramalho 59, 7000-671 Évora, Portugal

A. V. Dordio

IMAR - Marine and Environmental Research Centre, University of

Évora, Rua Romão Ramalho 59, 7000-671 Évora, Portugal

J. P. P. Ramalho

CGE - Centro de Geofísica de Évora, University of Évora, Rua

Romão Ramalho 59, 7000-671 Évora, Portugal used efficiently as filter medium to remove these pollutants from water and wastewater.

Keywords Adsorption · Benzodiazepines · Clay minerals · DFT $\cdot$ PAW $\cdot$ Vermiculite

\section{Introduction}

Benzodiazepines (BDZs) belong to the group of psychiatric substances which act on the central nervous system, having anxiolytic, sedative, and hypnotic effects and it is one of the most prescribed groups of pharmaceuticals throughout the world. Moreover, these compounds are not used exclusively for human therapeutics. In fact, their prescription is also common in veterinary treatments for anxiolytic and appetite stimulation effects.

There are several BDZs presently in use for therapeutic purposes, and the effects of the widespread consumption of these compounds extend to several facets of human life, including potential environmental and ecotoxicological issues [1-4]. Indeed, trace levels of BDZs can now be found disseminated on the environment, thus becoming a matter of ecological concern [1-6]. Over the last decade, there has been a significant number of studies reporting the occurrence of BDZs in environmental matrices, namely in wastewater treatment plants influents and effluents, surface waters, and drinking waters [5-11]. Some of the more frequently detected BDZs include alprazolam, diazepam, lorazepam, and oxazepam [5-11].

The main reason for the ubiquitous presence of BDZs in the environment is associated not only with the high consumptions of these drugs but also the generally low efficiency of conventional biological wastewater treatment processes to remove these pharmaceutical residues [5-7]. It has been suggested that this inefficiency is due to the halogenated structure 
of these compounds that significantly reduces their susceptibility to biodegradation [12]. Adsorption processes are the most promising and cheap alternative for removal of this kind of organic xenobiotics from wastewaters. In recent years, inexpensive widely available materials have been investigated for the selection of efficient adsorbents that can make adsorption processes an attractive solution at reasonable costs. Among some of the adsorbents studied, clay-based materials have received some attention [13-19] due to their interesting properties such as the high cation exchange capacity, swelling properties, and high specific surface areas. In particular for the treatment of wastewaters, these materials can overcome the limitations of biological processes, as used in conventional wastewater treatment. A better understanding of the interactions of these organic molecules with clay minerals may thus allow a more judicious selection of materials to be made for application as water/wastewater treatment filters that present significant enhancements in the removal of BDZs. In addition, given the fact that clay minerals are an important component of most types of soils, a better characterization of the interactions of these substances with clay surfaces may contribute to understanding the fate of these pollutants in the environment, in particular by allowing a better description of the partition phenomena between the aquatic and soil compartments. In this regard, quantum chemical studies that can achieve the most accurate and detailed description of electronic and atomic level phenomena can be a valuable tool to discern the several aspects that can contribute to a more clear understanding of these processes. Specifically, these methods can elucidate on which sites adsorption to a surface occurs at, the relative stabilities of the different binding sites and geometrical details that take place on the adsorbate and on the surface upon adsorption.

In this work, electronic structure calculations based on the density functional theory (DFT) are presented on the interaction of two representative BDZ molecules, diazepam (DZP) and alprazolam (APZ) (chemical structures in Fig. 1), with a periodic model surface of a clay mineral, vermiculite. Geometry changes of the molecules upon adsorption were compared and the interaction energies with the surfaces were determined for a few different molecular orientations in order to understand the way these molecules interact with the clay surface and the essential factor governing the adsorption processes.

\section{Computational details}

A theoretical study of the interactions between adsorbing molecules of APZ and DZP with a vermiculite surface was carried out by density functional theory (DFT) calculations. This study was performed using the plane-wave based VASP software [20] with the Perdew-Burke-Ernzerhof (PBE) generalized-gradient approximation of the exchange-

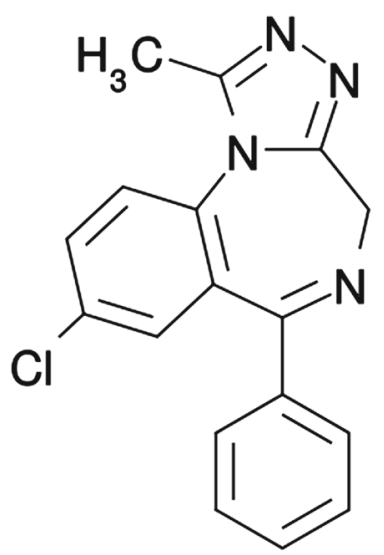

Alprazolam

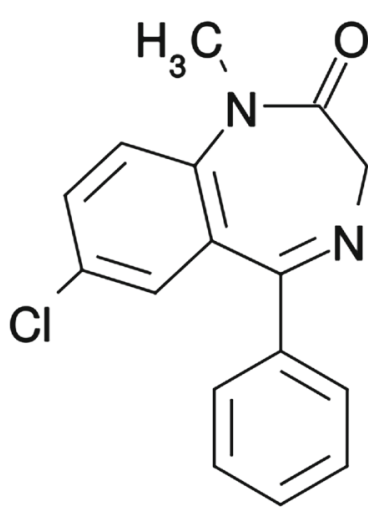

Diazepam
Fig. 1 Chemical structures of the studied benzodiazepines, alprazolam (left) and diazepam (right)

correlation functional [21] on a periodic slab model of the vermiculite surface. Density-functional theory calculations with different flavors of the generalized gradient approximation (GGA) for the exchange-correlation functional have been extensively used in molecules on surface studies. The PBE functional in particular has recently been employed successfully in studies of siliceous materials $[22,23]$ and, in particular, in the adsorption of organic molecules to clays [24-26].

A plane-wave basis set with an energy cutoff of $450 \mathrm{eV}$ was employed and the electron-ion interactions were represented through the projector augmented-wave (PAW) method of Blöchl [27] as implemented in VASP [28].

The model of the vermiculite surface was constructed based on a structure derived from crystallographic data reported by Shirozu and Bailey [29] as available in the American Mineralogist Crystal Structure Database [30]. Vermiculite is a 2:1 clay, i.e., with two tetrahedral sheets for each octahedral sheet. Vermiculites contain either $\mathrm{Al}^{3+}$ or $\mathrm{Mg}^{2+}$ and $\mathrm{Fe}^{2+}$ as normal octahedral ions, and substitution of some $\mathrm{Si}^{4+}$ ions by $\mathrm{Al}^{3+}$ occurs in tetrahedral sheets. The negative charge caused by substitutions is neutralized by various hydrated cations present in the interlayer space.

In the model used in the calculations, the octahedral ions consisted exclusively of $\mathrm{Mg}^{2+}$ and silicon was substituted by aluminum in a 1:3 ratio. The resulting net lattice charge was neutralized with hydrated $\mathrm{Mg}^{2+}$, thus yielding a chemical formula of $\mathrm{Mg}_{3} \mathrm{Si}_{3} \mathrm{AlO}_{10}(\mathrm{OH})_{2} \cdot\left[\mathrm{Mg}\left(\mathrm{H}_{2} \mathrm{O}\right)_{6}\right]_{1 / 2}$. The model slab consisted of a single T-O-T layer but due to the large size of the adsorbed molecules a single unit cell of the starting structure had to be expanded by replication into a $2 \times 2 \times 1$ super-cell, which was defined by the following lattice parameters (of a monoclinic structure): $a=10.698 \AA, b=18.510 \AA$, $c=35.000 \AA$, and $\beta=97.12^{\circ}$. The vacuum thickness assured by this box is sufficiently large to avoid any noticeable interaction between the repeated slabs and is large enough to obtain meaningful results by considering the $\Gamma$-point of the reciprocal space only. 
During the calculations, the internal slab atoms were kept fixed at the bulk positions obtained from crystallographic data while the atoms in the top surface were allowed to relax in order to "adjust" to the molecules adsorption. The set of atoms with freedom to move in optimization included the adsorbed hydrated $\mathrm{Mg}^{2+}$ ions and, of course, the adsorbing molecules of APZ or DZP.

Several initial structures were considered for the location of the adsorbates. The APZ and DPZ molecules were placed initially with electron-donating atoms $(\mathrm{N}$ or $\mathrm{O})$ located over one atom of each of the surface atom types $(\mathrm{Al}, \mathrm{Si}$, or $\mathrm{O})$ and, additionally, over one of the external hydrated $\mathrm{Mg}^{2+}$ cations. The choice of these starting structures can be justified with the fact that previous studies on the adsorption of other small organic molecules to the surface of clay minerals ranked the interactions between organic adsobate's heteroatoms and the clay's external cations to be the strongest among all types considered [24].

Subsequent calculations were performed on a simplified system to better study the interactions of the adsorbing molecules and the surface $\mathrm{Mg}^{2+}$ cations, in which case the hydration water molecules of these cations were removed and the whole procedure was repeated as in the previous calculations.

Adsorption energies were calculated by:

$\Delta E_{\text {Ads }}=E_{\text {Surf-Adsor }}-\left(E_{\text {Surf }}+E_{\text {Adsor }}\right)$

where $E_{\text {Surf-Adsor }}$ is the energy of the geometry-optimized surface+adsorbate (OSA) system, $E_{\text {Surf }}$ is the energy of a separately optimized surface (including the hydrating water molecules when appropriate) and $E_{A d s o r}$ is the energy of a separately optimized molecule in the gas phase. The energy of all the systems (isolated molecules, isolated surface, and surface+adsorbate systems) have been calculated using unit cells of the same size and same energy cutoffs.

In addition, adsorbate-adsorbent interaction energies were also calculated for the non-hydrated $\mathrm{Mg}^{2+}$ systems by:

$\Delta E_{\text {Int }}=E_{\text {Surf-Adsor }}-\left(E_{\text {Surf } *}+E_{\text {Adsor* } *}\right)$

where $E_{\text {Surf-Adsor }}$ is the energy of the OSA system (identical to $E_{\text {Surf-Adsor }}$ above), whereas $E_{\text {Surf* }}$ is the energy (i.e., singlepoint calculation) of the surface in the same configuration that results from the surface+ adsorbate optimization (i.e., the configuration of the OSA system with the adsorbate atoms removed) and $E_{A d s o r} *$ is the energy (i.e., single-point calculation as well) of the adsorbate molecule in the adsorbed configuration (i.e., as obtained from the OSA system, without any further optimization in vacuum/gas phase). $E_{S u r f *}$ and $E_{A d s o r *}$ were calculated in unit cells of the same size and using the same energy cutoffs as employed for the OSA systems.
Energies of deformation of the adsorbate molecules and of the surfaces as a result of their interaction upon the adsorption process were also calculated, corresponding to the differences between the optimized isolated components and the corresponding configurations as obtained in the OSA systems, i.e., $E_{\text {Adsor }}-E_{A d s o r} *$ and $E_{\text {Surf }}-E_{\text {Surf* }}$ respectively.

\section{Results and discussion}

Relevant initial configurations of the adsorbates were sampled by placing electron-donating atoms $(\mathrm{N}$ or $\mathrm{O})$ of the adsorbates over one atom of each of the surface atom types $(\mathrm{Al}, \mathrm{Si}, \mathrm{O})$ and, additionally, over one of the external $\mathrm{Mg}^{2+}$ cations.

Starting from these initial configurations, the systems were permitted to relax by allowing modification of the positions of all of the adsorbate's atoms as well as of the surface's upper layer of atoms and the top $\mathrm{Mg}^{2+}$ cations (including their hydration waters in the case of the hydrated systems), until an energy minimized structure was obtained.

Systems with hydrated $\mathrm{Mg}^{2+}$ surface cations

From all the initial configurations of the systems with hydrated $\mathrm{Mg}^{2+}$ surface cations, only two of them evolved to configurations with favorable (negative) adsorption energies (Table 1). The resulting structures of these adsorbed systems are depicted in Fig. 2, and the main features of the optimized geometries, namely the distances between the atoms which are involved in the binding between the adsorbates and the surface, are presented in Table 2.

It can be observed that under the influence of the adsorbate molecules over the surfaces, the $\mathrm{Mg}^{+}$ions are slightly lifted from the surface. In the final energy minimized configurations of these systems, the only one that resulted in a favorable adsorption energy case was characterized, for both molecules, by departure from contact distance with the surface to a longer distance, and bound to the surface by means of a water molecule establishing a bridge through $\mathrm{H}$-bonds to a $\mathrm{N}$ atom of the molecule on one side and to an $\mathrm{O}$ atom of the surface on the other (Fig. 2).

In regard to the starting configuration set over the hydrated $\mathrm{Mg}^{2+}$ cation, the energy minimized result also appears to be energetically favorable in the case of both molecules, with the cation thereby bridging the binding of the molecules to the surface. However, in comparison, this cation-bridge interaction seems weaker than the water H-bonds mediated adsorption (Table 1).

For the two adsorbates taken in comparison, the calculations suggest that DZP has a stronger affinity for the vermiculite surface. Bonded to it either by cation bridge or H-bonds, the adsorption energies are more negative in both configurations than they are for the case of the APZ molecule. 
Table 1 Energies $\left(\mathrm{kJ} \mathrm{mol}^{-1}\right)$ of adsorption and (only for the non-hydrated $\mathrm{Mg}^{2+}$ systems) of surface-adsorbate interaction. In addition, energies due to the adsorbates and surface deformations to accommodate the adsorption phenomena are also presented

\begin{tabular}{|c|c|c|c|c|c|c|c|c|}
\hline & $\mathrm{Mg}$ bridge & & & & H-bonds & & & \\
\hline a & $\Delta E_{A d s}^{\mathrm{b}}$ & $\Delta E_{I n t}{ }^{\mathrm{c}}$ & $\Delta E_{D \text { mol }}^{\mathrm{d}}$ & $\Delta E_{D \text { surf }}^{\mathrm{e}}$ & $\Delta E_{A d s}^{\mathrm{b}}$ & $\Delta E_{\text {Int }}^{\mathrm{c}}$ & $\Delta E_{D \text { mol }}^{\mathrm{d}}$ & $\Delta E_{D \text { surf }}^{\mathrm{e}}$ \\
\hline $\mathrm{APZ}_{h}$ & -9.27 & & & & -41.57 & & & \\
\hline $\mathrm{APZ}_{n h}$ & -101.56 & -154.37 & 11.77 & 41.04 & & & & \\
\hline $\mathrm{DZP}_{h}$ & -24.07 & & & & -56.44 & & & \\
\hline $\mathrm{DZP}_{n h}$ & 28.34 & -163.00 & 16.42 & 174.92 & 30.93 & -97.41 & 117.29 & 11.05 \\
\hline
\end{tabular}

${ }^{a}$ indices $h$ refer to systems with all hydrated surface $\mathrm{Mg}^{2+}$ cations (according to Fig. 2); indices $n h$ refer to systems where, on the adsorbate side of the surface, $\mathrm{Mg}^{2+}$ cations are not hydrated (according to Fig. 3)

${ }^{\mathrm{b}}$ Adsorption energy, as defined by Eq. (1)

${ }^{\mathrm{c}}$ Interaction energy, as defined by Eq. (2)

${ }^{\mathrm{d}}$ Deformation energy of the adsorbate, as defined in the text (computational details)

${ }^{\mathrm{e}}$ Deformation energy of the surface, as defined in the text (computational details)
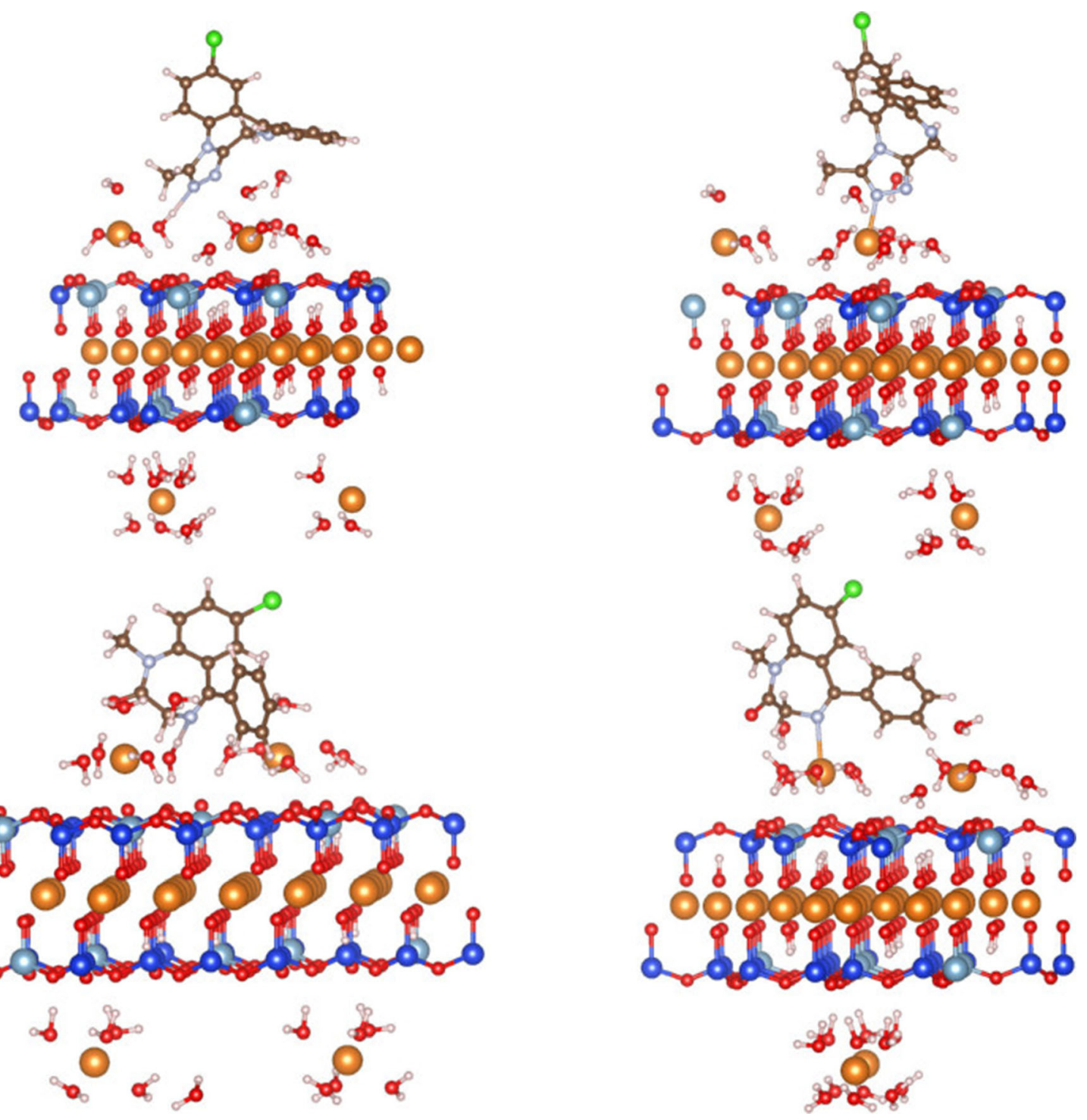

Fig. 2 Energy minimized geometries of the hydrated $\mathrm{Mg}^{2+}$ surface cations systems: alprazolam adsorbate on top structures, diazepam adsorbate on bottom structures; water-bridge binding on left structures, and $\mathrm{Mg}^{2+}$-bridge binding on right structures 
Table 2 Features of the optimized geometries of APZ and DZP adsorbed to hydrated and non-hydrated vermiculite. Also the average distances to the surface of hydrated and non-hydrated surface $\mathrm{Mg}^{2+}$ cations are presented. Surface level is taken as the average $z$ position of the outer surface oxygens. Negative distances to the surface mean positions which are below the surface level (toward the interior of the vermiculite slab)

\begin{tabular}{|c|c|c|c|c|c|c|c|c|c|}
\hline \multirow[b]{3}{*}{ Distances } & \multicolumn{5}{|c|}{ Hydrated } & \multicolumn{4}{|c|}{ Non-hydrated } \\
\hline & \multirow{3}{*}{$\begin{array}{l}\text { Surf }^{\mathrm{d}} \\
2.078\end{array}$} & \multicolumn{2}{|l|}{$\mathrm{APZ}$} & \multicolumn{2}{|l|}{ DZP } & \multirow{3}{*}{$\begin{array}{l}\text { Surf }^{d} \\
-0.183\end{array}$} & \multirow{2}{*}{$\begin{array}{l}\text { APZ } \\
\text { Mg bridge }\end{array}$} & \multicolumn{2}{|l|}{ DZP } \\
\hline & & Mg bridge & Water bridge & Mg bridge & Water bridge & & & Mg bridge & H-bond bridge \\
\hline Mg-Surf & & $\begin{array}{l}2.152 \\
2.184\end{array}$ & $\begin{array}{l}1.896 \\
2.160\end{array}$ & $\begin{array}{l}2.003 \\
2.222\end{array}$ & $\begin{array}{l}1.961 \\
2.185\end{array}$ & & -0.206 & -0.254 & -0.218 \\
\hline Mol-Surf ${ }^{a}$ & & $4.312(\mathrm{~N})$ & $4.336(\mathrm{~N})$ & $4.521(\mathrm{C})$ & $3.255(\mathrm{C})$ & & $2.361(\mathrm{~N})$ & $2.797(\mathrm{C})$ & $2.551(\mathrm{O})$ \\
\hline$X-Y^{b}$ & & $2.212(\mathrm{~N}-\mathrm{Mg})$ & $1.766(\mathrm{~N}-\mathrm{H})$ & $2.451(\mathrm{~N}-\mathrm{Mg})$ & $1.776(\mathrm{~N}-\mathrm{H})$ & & $2.109(\mathrm{~N}-\mathrm{Mg})$ & $2.170(\mathrm{~N}-\mathrm{Mg})$ & $1.024(\mathrm{O}-\mathrm{H})$ \\
\hline Y-Surf ${ }^{c}$ & & $2.152(\mathrm{Mg})$ & $2.417(\mathrm{Ow})$ & $2.222(\mathrm{Mg})$ & $2.167(\mathrm{Ow})$ & & $0.360(\mathrm{Mg})$ & $0.986(\mathrm{Mg})$ & $1.583(\mathrm{H})$ \\
\hline
\end{tabular}

${ }^{a}$ distance of the non-hydrogen atom of the molecule nearest to the surface (atom type given in parenthesis)

${ }^{\mathrm{b}}$ distance between pair of atoms involved in the bridge structure (identity of the involved atoms $\mathrm{X}$ and $\mathrm{Y}$ are given in parenthesis)

${ }^{\mathrm{c}}$ distance of the bridging molecule/atom to the surface (the type of atom $\mathrm{Y}$ is given in parenthesis; Ow meaning that the water oxygen is taken as reference position of the molecule)

d clean surface, without adsorbate

Fig. 3 Energy minimized geometries of the non-hydrated $\mathrm{Mg}^{2+}$ surface cations systems: alprazolam adsorbate on top structure showing $\mathrm{Mg}^{2+}$-bridge binding; diazepam adsorbate on bottom structures, with $\mathrm{Mg}^{2+}$ bridge on left and $\mathrm{H}$-bond-bridge on right
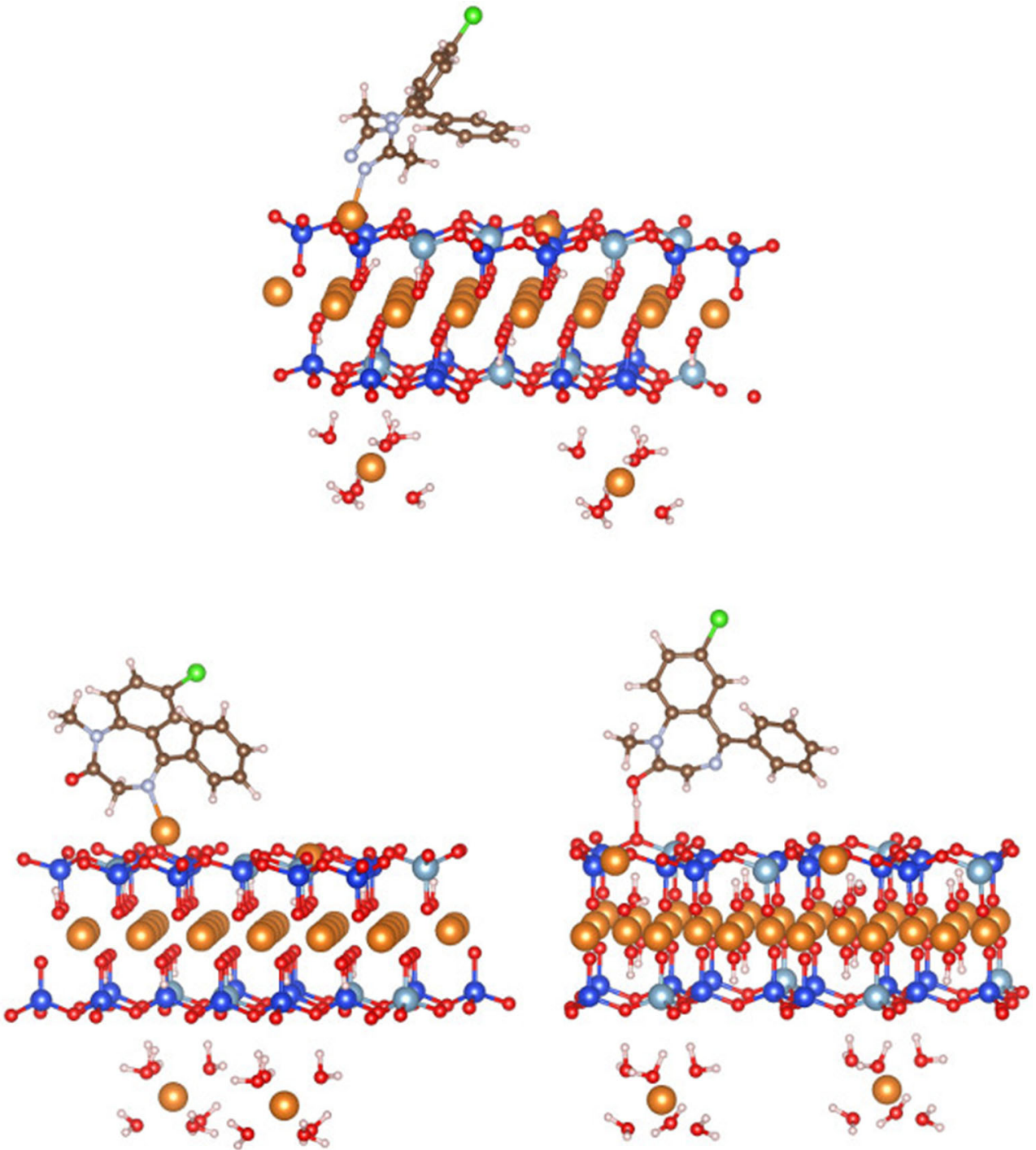
Systems with non-hydrated surface $\mathrm{Mg}^{2+}$ cations

Calculations were also performed on simplified systems without the hydration waters of the cations on the side of the surface in contact with the molecules (Fig. 3). Although unrealistic, since in real applications these systems are always hydrated, these calculations are useful for better illustrating the extent of the $\mathrm{Mg}^{2+}$ interactions with the molecules and for better characterizing the cations' role in the adsorption process.

In the absence of the hydration of the $\mathrm{Mg}^{2+}$ cations in the vicinity of the adsorbates, there are no water molecules to provide a bridge between the molecules and the surface through H-bonds. For APZ, a cation bridge is the only provided mechanism for adsorption of the molecule to vermiculite. However, in the case of DZP, two different bindings are found: in addition to the cation bridge structure, a kind of tautomeric modification is observed as a result of the energy minimization procedure, where a $\mathrm{H}$ atom transfers from a neighboring $\mathrm{CH}_{2}$ group to the carbonyl group and subsequently provides a $\mathrm{H}$-bond between the carbonyl's $\mathrm{O}$ atom of the adsorbate and an $\mathrm{O}$ atom of the surface (Fig. 3). Of all these energy minima, however, only the APZ configuration corresponds to negative adsorption energies at this level of theory whereas both structures obtained for DZP seem less favorable for the adsorption of this molecule to vermiculite. The reasons for this observation can be understood by considering the energies of adsorbate-surface interaction (as defined in the methods section) and the deformation energies for the adsorbate molecules and for the surfaces. In fact, the interaction energy between a DZP molecule and the surface is somewhat more negative than in the case of APZ. However, as a result of not being hydrated, the $\mathrm{Mg}^{2+}$ cations coalesce into the surface of the vermiculite slab during the energy minimization, but the DZP molecule has the effect of pulling one $\mathrm{Mg}^{2+}$ cation off the surface (Fig. 3 and Table 2) which results in a sufficiently positive energy associated with this deformation of the surface to also yield a positive value for the adsorption energy. In regard to the other minimum, the adsorbate-surface interaction energy for this structure is also very negative (although much lower in absolute value than the Mg-bridged interaction) but in this case it is the deformation of the adsorbate molecule that is very unfavorable, due to the involvement of a $\mathrm{H}$ transfer as described above.

Overall, the strong adsorbate-surface interactions obtained for all of these configurations are in line with the adsorption energies yielded in the fully-hydrated $\mathrm{Mg}^{2+}$ systems and follow the qualitative trends observed in the former cases. However, the significant modifications that occur in the absence of the water molecules in latter cases are responsible for the positive adsorption energies observed for DZP in these unrealistic situations. Nevertheless, these calculations reaffirm the strong interactions of the molecules with the $\mathrm{Mg}^{2+}$ bridge and
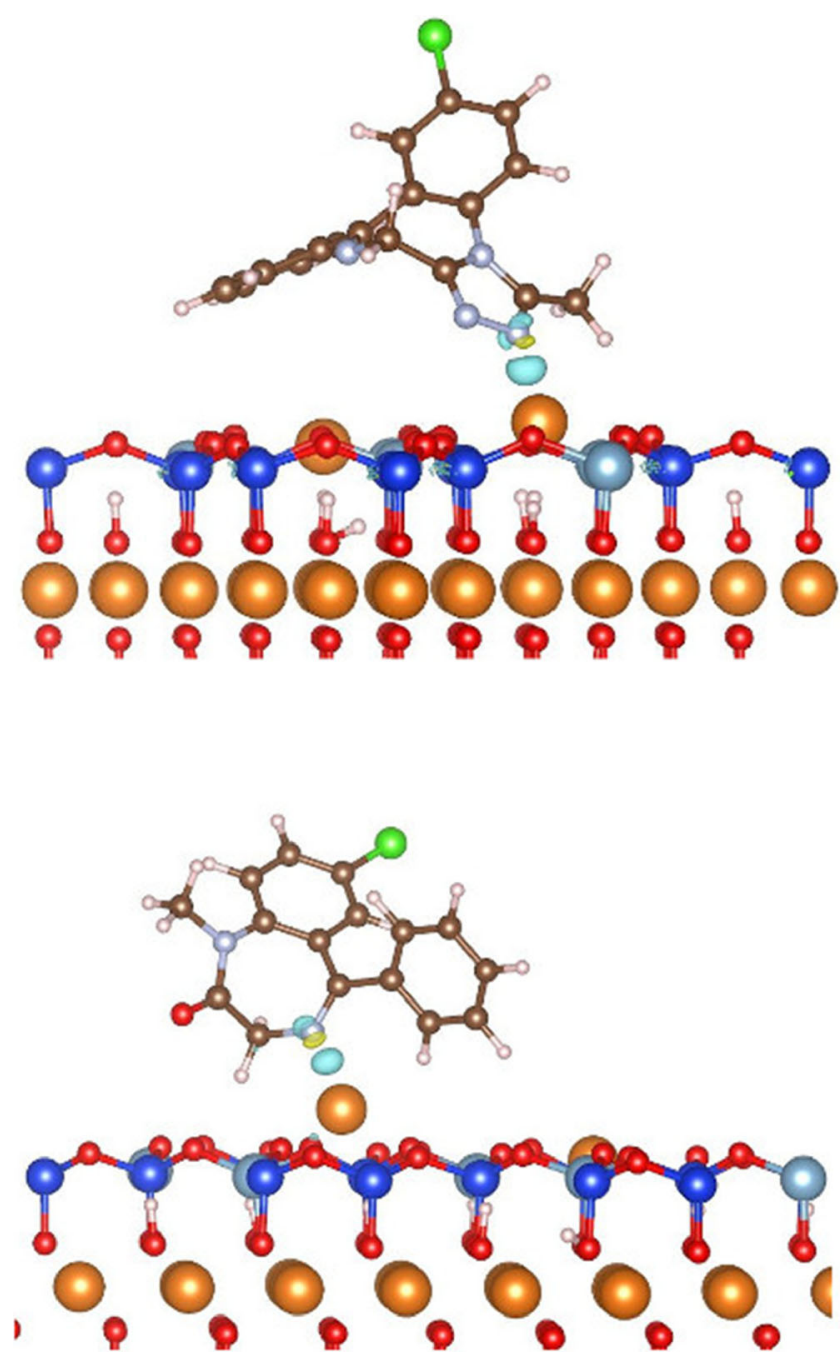

Fig. 4 Electron density difference between the adsorbed AZP (top) and DZP (bottom) and the separated systems. The yellow and light blue regions correspond to electron depletion and accumulation, respectively. The isosurface values are -0.003 and $+0.003 \mathrm{e} / \AA^{3}$

the preference toward DZP. It is interesting to note that the importance of cation-bridge structures has also been evidenced in a previous study on the adsorption of DNA/RNA bases to a different clay surface, montmorillonite [24]. In that work the electrostatic type of interactions between the nucleobases' heteroatoms $(\mathrm{N}$ or $\mathrm{O})$ and the $\mathrm{Na}^{+}$cation of the surface are found to be the most energetic among all the other studied possibilities. In fact, in comparison, the adsorption energy obtained in this work for AZP interacting through a $\mathrm{N}$ atom with the non-hydrated $\mathrm{Mg}^{2+}$ cation $\left(-101.6 \mathrm{~kJ} \mathrm{~mol}^{-1}\right)$ is of the same order as the adsorption energy of, e.g., the guanine base interacting with a $\mathrm{Na}^{+}$cation through the same heteroatom $\left(-90.4 \mathrm{~kJ} \mathrm{~mol}^{-1}\right)$.

Further insights into the adsorbate-substrate interaction were gained by analyzing the atomic charges obtained from the "atoms in molecules" (AIM) topological analysis of Bader [31]. 
Calculating the Bader charges of the free and adsorbed molecules by summing over the partial Bader charges of the corresponding atoms one can estimate the charge transfer that occurs between the molecules and the surface upon adsorption. Upon conclusion of this calculation, a charge transfer of 0.053 electrons from APZ to the surface was observed, whereas in the case of DZP the charge transfer was only of 0.036 electrons. The small amount of charge transferred upon adsorption is in agreement with the calculated adsorption energies.

A more comprehensive picture of the interaction between the molecules with the surface results from analysis of the electron density difference defined as:

$\Delta \rho(r)=\rho_{\text {Surf-Adsor }}(r)-\rho_{\text {Surf }}(r)-\rho_{\text {Adsor }}(r)$

where $\rho_{\text {Surf-Adsor }}(r)$ is the electronic density of the adsorbate covered surface and $\rho_{\text {Sur }}(r)$ and $\rho_{\text {Adsor }}(r)$ are the densities of the surface and the adsorbate respectively. This difference of the electronic densities illustrates the electronic reorganization that results from adsorption. Electron density difference plots are depicted in Fig. 4 for the APZ and DZP adsorption through the $\mathrm{Mg}^{2+}$ bridge case. It is clear from the picture that the small charge transfer comes from the molecules' nitrogen toward the magnesium cation.

\section{Conclusions}

The adsorption of two benzodiazepine molecules, diazepam and alprazolam, on a periodic model surface of vermiculite has been studied by periodic DFT methods. It was observed that adherence of these molecules to the vermiculite surface can be attained by two effects, through bridging by $\mathrm{Mg}^{2+}$ cations or by a water molecule via $\mathrm{H}$-bonds to the molecules and to the surface. When comparing the two adsorbates, the calculations suggest that DZP has a stronger affinity for the vermiculite surface. Bader charges analysis showed that in both cases a small charge is transferred from the molecules to the surface.

Further developments on the present model can be devised, for instance, a more refined model where full hydration of the system is considered as well as the study of the process in the interlayer space between two vermiculite sheets (which allows the modeling of intercalation processes in the expandable structure of vermiculite) may provide a more realistic assessment of organic molecules' adsorption phenomena onto this clay mineral. Work along these lines is currently underway.

Vermiculite is a mineral with both ingredients to provide efficient capture of these two compounds by adsorption phenomena, namely it is an extensively hydrated mineral and it possesses abundant exchangeable cations on its surfaces, both of which can provide the bridging effects that have been observed in this work and, consequently, a strong interaction between the adsorbates and the surface. This study suggests vermiculite as a promising and cheap alternative for removal of these drugs from waters and wastewaters through adsorption processes.

\section{References}

1. Brodin T, Fick J, Jonsson M, Klaminder J (2013) Dilute concentrations of a psychiatric drug alter behavior of fish from natural populations. Science 339:814-815

2. Dong Z, Senn DB, Moran RE, Shine JP (2013) Prioritizing environmental risk of prescription pharmaceuticals. Regul Toxicol Pharmacol 65:60-67

3. de Almeida CA, Brenner CGB, Minetto L, Mallmann CA, Martins AF (2013) Determination of anti-anxiety and anti-epileptic drugs in hospital effluent and a preliminary risk assessment. Chemosphere 93: 2349-2355

4. Gust M, Fortier M, Garric J, Fournier M, Gagné F (2013) Effects of short-term exposure to environmentally relevant concentrations of different pharmaceutical mixtures on the immune response of the pond snail Lymnaea stagnalis. Sci Total Environ 445-446:210-218

5. Fent K, Weston AA, Caminada D (2006) Ecotoxicology of human pharmaceuticals. Aquat Toxicol 76:122-159

6. Calisto V, Esteves VI (2009) Psychiatric pharmaceuticals in the environment. Chemosphere 77:1257-1274

7. Kosjek T, Perko S, Zupanc M, Zanoški Hren M, Dragicevic TL, Žigon D, Kompare B, Heath E (2012) Environmental occurrence, fate and transformation of benzodiazepines in water treatment. Water Res 46:355-368

8. González Alonso S, Catalá M, Maroto RR, Gil JLR, de Miguel ÁG, Valcárcel Y (2010) Pollution by psychoactive pharmaceuticals in the rivers of Madrid metropolitan area (Spain). Environ Int 36:195-201

9. Huerta-Fontela M, Galceran MT, Ventura F (2010) Fast liquid chromatography-quadrupole-linear ion trap mass spectrometry for the analysis of pharmaceuticals and hormones in water resources. J Chromatogr A 1217:4212-4222

10. Baker DR, Kasprzyk-Hordern B (2013) Spatial and temporal occurrence of pharmaceuticals and illicit drugs in the aqueous environment and during wastewater treatment: new developments. Sci Total Environ 454-455:442-456

11. Mendoza A, López de Alda M, González-Alonso S, Mastroianni N, Barceló D, Valcárcel Y (2014) Occurrence of drugs of abuse and benzodiazepines in river waters from the Madrid region (central Spain). Chemosphere 95:247-255

12. Johnson AC, Jurgens MD, Williams RJ, Kummerer $\mathrm{K}$, Kortenkamp A, Sumpter JP (2008) Do cytotoxic chemotherapy drugs discharged into rivers pose a risk to the environment and human health? An overview and UK case study. J Hydrol 348:167-175

13. Figueroa RA, Leonard A, Mackay AA (2004) Modeling tetracycline antibiotic sorption to clays. Environ Sci Technol 38: 476-483

14. Dordio AV, Candeias AJE, Pinto AP, da Costa CT, Carvalho AJP (2009) Preliminary media screening for application in the removal of clofibric acid, carbamazepine and ibuprofen by SSF-constructed wetlands. Ecol Eng 35:290-302

15. Zhang WH, Ding YJ, Boyd SA, Teppen BJ, Li H (2010) Sorption and desorption of carbamazepine from water by smectite clays. Chemosphere 81:954-960 
16. Park Y, Ayoko GA, Frost RL (2011) Application of organoclays for the adsorption of recalcitrant organic molecules from aqueous media. J Colloid Interface Sci 354:292-305

17. Li ZH, Chang PH, Jiang WT, Jean JS, Hong HL, Liao LB (2011) Removal of diphenhydramine from water by swelling clay minerals. J Colloid Interface Sci 360:227-232

18. Behera SK, Oh SY, Park HS (2012) Sorptive removal of ibuprofen from water using selected soil minerals and activated carbon. Int $\mathrm{J}$ Environ Sci Technol 9:85-94

19. Dordio AV, Carvalho AJP (2013) Organic xenobiotics removal in constructed wetlands, with emphasis on the importance of the support matrix. J Hazard Mater 252-253:272-292

20. Kresse G, Hafner J (1993) Ab initio molecular dynamics for liquid metals. Phys Rev B 47:558-561

21. Perdew JP, Burke K, Ernzerhof M (1996) Generalized gradient approximation made simple. Phys Rev Lett 77:3865-3868

22. Goumans TPM, Wander A, Brown WA, Catlow CRA (2007) Structure and stability of the (001) $\alpha$-quartz surface. Phys Chem Chem Phys 9:2146-2152

23. Vener MV, Rozanska X, Sauer J (2009) Protonation of water clusters in the cavities of acidic zeolites: $\left(\mathrm{H}_{2} \mathrm{O}\right)_{\mathrm{n}} \bullet \mathrm{H}$-chabazite, $n=1-4$. Phys Chem Chem Phys 11:1702-1712
24. Mignon P, Ugliengo P, Sodupe M (2009) Theoretical study of the adsorption of RNA/DNA bases on the external surfaces of $\mathrm{Na}^{+}$montmorillonite. J Phys Chem C 113:13741-13749

25. Mignon P, Sodupe M (2012) Theoretical study of the adsorption of DNA bases on the acidic external surface of montmorillonite. Phys Chem Chem Phys 14:945-954

26. El Adraa K, Timon V, Lambert JF, Al Rabaa AR, Jaber F, Jaber M, Tielens F (2012) Adsorption of L-DOPA intercalated in hydrated Nasaponite clay: a combined experimental and theoretical study. J Phys Chem C 116:26414-26421

27. Blöchl PE (1994) Projector augmented-wave method. Phys Rev B 50:17953-17979

28. Kresse G, Joubert D (1999) From ultrasoft pseudopotentials to the projector augmented-wave method. Phys Rev B 59:17581775

29. Shirozu H, Bailey SW (1966) Crystal structure of a two-layer Mgvermiculite. Am Miner 51:1124-1143

30. Downs RT, Hall-Wallace M (2003) The American mineralogist crystal structure database. Am Miner 88:247-250

31. Tang W, Sanville E, Henkelman G (2009) A grid-based Bader analysis algorithm without lattice bias. J Phys -Condes Matter 21 